\title{
Perception and beliefs about mental illness among adults in Karfi village, northern Nigeria
}

\author{
Mohammed Kabir ${ }^{1}$, Zubair Iliyasu ${ }^{1}$, Isa S Abubakar ${ }^{1}$ and Muktar H Aliyu*1,2
}

Address: ${ }^{1}$ Department of Community Medicine, Aminu Kano Teaching Hospital, Kano, Nigeria \& Department of Community Medicine \& Primary Care, Bayero University, Kano, Nigeria and 2Department of Epidemiology, School of Public Health, University of Alabama at Birmingham, USA

Email: Mohammed Kabir - mdkabir@ecnx.net; Zubair Iliyasu - ziliyasu@yahoo.com; Isa S Abubakar - abumusadiq@yahoo.co.uk; Muktar H Aliyu* - mhaliyu@uab.edu

* Corresponding author

Published: 20 August 2004

BMC International Health and Human Rights 2004, 4:3 doi: 10.1 186/1472-698X-4-3

This article is available from: http://www.biomedcentral.com//472-698X/4/3

(C) 2004 Kabir et al; licensee BioMed Central Ltd.

This is an open-access article distributed under the terms of the Creative Commons Attribution License (http://creativecommons.org/licenses/by/2.0), which permits unrestricted use, distribution, and reproduction in any medium, provided the original work is properly cited.
Received: 15 June 2004

Accepted: 20 August 2004

\begin{abstract}
Background: This study was designed to examine the knowledge, attitude and beliefs about causes, manifestations and treatment of mental illness among adults in a rural community in northern Nigeria.
\end{abstract}

Methods: A cross sectional study design was used. A pre-tested, semi-structured questionnaire was administered to 250 adults residing in Karfi village, northern Nigeria.

Results: The most common symptoms proffered by respondents as manifestations of mental illness included aggression/destructiveness (22.0\%), loquaciousness (21.2\%), eccentric behavior (16.1\%) and wandering (13.3\%). Drug misuse including alcohol, cannabis, and other street drugs was identified in $34.3 \%$ of the responses as a major cause of mental illness, followed by divine wrath/ God's will (19\%), and magic/spirit possession (18.0\%). About $46 \%$ of respondents preferred orthodox medical care for the mentally sick while $34 \%$ were more inclined to spiritual healing. Almost half of the respondents harbored negative feelings towards the mentally ill. Literate respondents were seven times more likely to exhibit positive feelings towards the mentally ill as compared to non-literate subjects $(\mathrm{OR}=7.6,95 \%$ confidence interval $=3.8-\mid 5 . \mathrm{I})$.

Conclusions: Our study demonstrates the need for community educational programs in Nigeria aimed at demystifying mental illness. A better understanding of mental disorders among the public would allay fear and mistrust about mentally ill persons in the community as well as lessen stigmatization towards such persons.

\section{Background}

Throughout the world, there is an increasing awareness of mental illness as a significant cause of morbidity [1]. This awareness has increased with the steady decline of morbidity due to nutritional disorders, communicable dis- eases and other forms of physical illness, especially in countries undergoing epidemiological transition [2].

Mental and behavioral disorders are common, affecting more than $25 \%$ of all people at some time during their 
lives [3]. They are also universal, affecting people of all countries and societies, regardless of age, gender and income. The point prevalence of mental illness in the adult population at any given time is about $10 \%$ [3]. Similarly, around $20 \%$ of all patients seen by primary health care providers have one or more mental health disorders [3].

The role of the community in the prevention and care of the mentally handicapped has now been widely acknowledged and is regarded as the most appropriate basis for the development of mental health programs. Several studies have shown that knowledge of public attitude to mental illness and its treatment is a vitally important prerequisite to the realization of successful communitybased programs [4-6]. The recognition of mental disorder also depends on a careful evaluation of the norms, beliefs and customs within the individual's cultural environment. Furthermore, community attitude and beliefs play a role in determining help-seeking behavior and successful treatment of the mentally ill. Unarguably, ignorance and stigma prevent the mentally ill from seeking appropriate help.

People tend to have strong beliefs about the mentally ill, and many of these concepts are based on prevailing local systems of belief [7]. In developing any mental health education program, the basis of such beliefs must be taken into consideration. People's beliefs regarding mental illness should not only be known, but the purpose of their beliefs should be understood. Such attitudes and beliefs about mental illness can only be studied within a cultural context. Although the knowledge and perception of mentally ill patients and their relatives regarding mental illness has been reported from southwest Nigeria [8], to date there is little research on public attitudes towards mental illness from northern Nigeria, a culturally distinct part of the country. This paper is therefore one of the first to report findings related to attitudinal research on mental illness from northern Nigeria.

The 1995 Nigeria National Mental Health Policy advocates the integration of mental health promotion, treatment and rehabilitation into primary health care services (PHC). However, this goal cannot be successfully achieved without an understanding of community attitudes towards mental illness. We therefore set out to ascertain the perceptions, attitudes and beliefs of adults regarding the causes, manifestations and treatment options of mental illness in a traditional Hausa community near Kano, Nigeria.

\section{Methods \\ Study area}

The study population included 250 adults residing at Karfi village, about 15 kilometers from Kano city. This typical Hausa community has 11,314 inhabitants [9]. Majority are Muslims preoccupied with farming and petty trading. About $32.0 \%$ of the populace are literate. The village has one primary health centre and several traditional healers. Referrals from the health centers are sent to Kura General Hospital and occasionally to Aminu Kano Teaching Hospital. Informed consent was obtained from respondents prior to commencement of the interviews.

\section{Study design}

A cross sectional descriptive study

\section{Sample size and sampling technique}

A multistage sampling technique was adopted. In the first stage, four wards out of the seven in the village were randomly selected. After house numbering, 250 houses were selected from the four wards using a table of random numbers. Where more than one household was found in a house, one household was selected by balloting. Finally, one adult was selected at random from each household for the interview. A final sample size of 250 adults was therefore obtained.

\section{Instrument description/ Data collection}

We adopted and modified a pre-existing semi-structured questionnaire [7] to evaluate the perceptions and beliefs of adults in Karfi village. The questionnaire was in three parts; the first section inquired about personal data including age, sex, ethnicity, religion, marital status, educational level and occupation; the second part elicited awareness of existence of mental illness in the community, knowledge of causal factors, manifestation of the disorder and awareness and preference of treatment options, while the third part explored the attitudes, beliefs and perception of the respondent towards the mentally ill. Attitudes such as fear, avoidance, anger, suspicion, mistrust, hostility were considered negative, whereas sympathetic attitude, willingness to care for a mentally ill relative or friend and tolerance were considered positive attitudes.

The study instrument was validated using a pilot study of 10 randomly selected households in a nearby village with similar demographic characteristics (Kumbotso). Results of the pilot study were used to modify content and wording of the questionnaire. Previously trained medical undergraduates fluent in Hausa language administered the questionnaires to the sample population.

\section{Data analysis}

The data was analyzed using the Epi-Info ${ }^{\circledast} 6.0$ statistical software package (CDC Atlanta, Georgia, USA). 
Descriptive statistics were depicted using absolute numbers, simple percentages, range, and measures of central tendency (mean, median) as appropriate. The Chi-square test was used to test the significance of associations between categorical groups. All tests of hypothesis were two-tailed with a type 1 error rate fixed at $5 \%$.

\section{Results}

In all, 250 respondents were interviewed with 167 males and 83 females giving a sex ratio of 2:1 in favor of males. Their ages ranged from 18 to 74 years. Majority (78.0\%) of the respondents were aged between 25 and 60 years. The median age $( \pm S D)$ for the respondents was $34.5 \pm 4.6$ years; $36.0 \pm 2.3$ years for males and $28.5 \pm 1.6$ years for females. The Hausa-Fulani ethnic group constituted $89 \%$ of respondents, and the rest were Yoruba 2.0\%, Igbo 5.0\% and other minority Nigerian tribes $4.0 \%$. About $16.0 \%$ of respondents had primary education, $12.0 \%$ had secondary education, and $4.0 \%$ had tertiary (post-secondary school) education. Approximately $27.0 \%$ of the population sampled had no formal education. Nevertheless, $41.0 \%$ of all respondents had Quranic education. The majority of respondents $(90.0 \%)$ were Muslims and the remaining $10.0 \%$ were Christians. About $10.0 \%$ were single, $80.0 \%$ were married, $6.0 \%$ were divorced and the remaining $4.0 \%$ were widowed. Forty eight per cent of the respondents were engaged in farming, $25.0 \%$ were fulltime housewives, $20.0 \%$ were engaged in petty trading, $7.0 \%$ were students and the remaining $4.0 \%$ were civil servants. About 13 persons interviewed (5.2\%) had a relative with mental illness, but because of the small sample size we did not separately analyze findings from this group of participants.

The most common symptoms proffered by respondents as manifestations of mental illness (Table 1) included aggression/destructiveness $(22.0 \%), \quad$ talkativeness (21.2\%), eccentric behaviour (16.1\%), and wandering $(13.3 \%)$. Drug misuse in form of alcohol ingestion, cannabis and other psychoactive street drugs were identified as major causes of mental illness $(34.3 \%)$, followed by effect of divine wrath or God's will $(18.8 \%)$, magic or spirit possession (18.0\%), and accidents/trauma (11.7\%) (Table 2). Heredity, family conflicts and financial distress/ poverty were uncommon responses.

The majority of respondents (46.0\%) opted for orthodox medical care when asked about preferred source of treatment for the mentally ill. This was followed by spiritual healing (exorcism) $(34.0 \%)$ and the use of traditional herbal medicines (18.0\%) (Table 3 ).

Table 4 shows that majority of the respondents harbored negative feelings towards the mentally ill, mainly in the form of fear $(n=113)$ and avoidance $(n=81)$. A total of
Table I: Respondents' perceived manifestations of mental disorder

\begin{tabular}{lll}
\hline Manifestation & No.* (\%) & Rank order \\
\hline Aggression/destructiveness & $173(22.0)$ & 1 \\
Talkativeness & $167(21.2)$ & 2 \\
Eccentric behavior & $127(16.1)$ & 3 \\
Wandering & $105(13.3)$ & 4 \\
Self-neglect & $86(10.9)$ & 5 \\
Nudity & $56(7.1)$ & 6 \\
Restlessness/anxiety & $50(6.4)$ & 7 \\
Insomnia & $15(1.9)$ & 8 \\
Loss of consciousness & $8(1.0)$ & 9 \\
\hline
\end{tabular}

* Multiple responses recorded. Percentages represent proportions of responses obtained.

Table 2: Perceived causes of mental illness

\begin{tabular}{lll}
\hline Perceived cause & No.* (\%) & Rank \\
\hline Misuse of drugst & $88(34.3)$ & 1 \\
Divine punishment, God's will & $48(18.8)$ & 2 \\
Magic, spirit possession & $46(18.0)$ & 3 \\
Accidents/trauma & $30(11.7)$ & 4 \\
Heredity & $27(10.5)$ & 5 \\
Family conflicts/marital disharmony & $14(5.5)$ & 6 \\
Financial distress/poverty & $3(1.2)$ & 7
\end{tabular}

*Multiple responses recorded. $\dagger$ Include street drugs and alcohol.

Table 3: Respondents' preferred treatment for mental illness

\begin{tabular}{ll}
\hline Response & No. (\%) \\
\hline Orthodox Medicine & $116(46.0)$ \\
Traditional Medicine & $46(18.0)$ \\
Spiritual Healing & $85(34.0)$ \\
Others & $3(2.0)$ \\
Total & $250(100.0)$ \\
\hline
\end{tabular}

117 respondents $(46.8 \%)$ were sympathetic towards the plight of the mentally sick with female respondents showing more inclination for sympathy compared to their male counterparts. The female respondents, however, tend to be fearful and avoid the mentally sick more than their male counterparts.

Literacy status was significantly associated with the type of feeling exhibited by the participants. Literate respondents were seven times more likely to exhibit positive feelings towards the mentally ill as compared to non-literate subjects $(\mathrm{OR}=7.6,95 \%$ confidence interval $=3.8-15.1)$ (Table 5). 
Table 4: Distribution of attitude towards the mentally ill by gender

\begin{tabular}{|c|c|c|c|}
\hline Attitude & Male & Female & Total \\
\hline & No. (\%) & No. (\%) & \\
\hline Fear & $24(20.8)$ & $89(79.2)$ & 113 \\
\hline Avoidance & $12(14.4)$ & $69(85.6)$ & 81 \\
\hline Anger & $48(96.8)$ & $2(3.2)$ & 50 \\
\hline Suspicion & $36(90.4)$ & $4(9.6)$ & 40 \\
\hline Hostility & $32(93.6)$ & $3(6.4)$ & 35 \\
\hline Mistrust & $28(89.6)$ & $4(10.4)$ & 32 \\
\hline Indifference & $16(96.0)$ & I (4.0) & 17 \\
\hline Sympathy & $39(33.6)$ & $78(66.4)$ & 117 \\
\hline Kindness & $17(20.8)$ & $62(79.2)$ & 79 \\
\hline
\end{tabular}

Table 5: Influence of literacy level of respondents on attitude towards the mentally ill

\begin{tabular}{lllll}
\hline & Positive attitude & Negative attitude & Total & Odds ratio (95\%Cl)* \\
\hline Literate & 92 & 15 & 107 & $7.6(3.8-15.1)$ \\
Not literate & 64 & 79 & 143 & 250 \\
Total & 156 & 94 & & \\
\hline
\end{tabular}

$* \mathrm{Cl}=$ confidence interval, $\mathrm{p}<0.000 \mathrm{I}$

\section{Discussion}

Aggression/destructiveness, talkativeness, and eccentric behaviors were the most frequently mentioned perceived symptoms of mental illness by respondents. This finding suggests that one has to display behaviour that attracts public attention and is therefore socially disruptive, to be recognized as having a mental disorder. This finding is similar to that documented by White in Tanzania [10] and Asuni et al. [7] among Yoruba patients in Western Nigeria. It is notable that hallucinations and delusions that are frequently mentioned in the literature as prototypes of gross psychotic states were not mentioned by the respondents as features of mental illness, probably because such features are not as tangible as aggressive attitudes.

Misuse of drugs ranked highest among the respondents as a perceived cause of mental disorders than most of the other traditional etiologies. This finding may not be unconnected with increasing use of illicit drugs among the youth in developing countries. Although drug abuse was acknowledged by Iliyasu and Last [11] in their work on mental illness in Kano, northern Nigeria as a leading cause of drug dependent psychosis, Holzinger and colleagues [12] reported that drugs and alcohol was not considered by schizophrenia patients or their relatives to be a common cause of mental illness. Divine punishment ranked second as a perceived causative factor. This response may not be unconnected with the leading response (drug misuse), as many individuals are of the belief that one evokes supernatural wrath by taking intoxicants thus leading to the development of mental illness [3].

Belief in demons as the cause of mental health problems is a well-known phenomenon in many cultures of the world [13] but in our study this factor was ranked $3^{\text {rd }}$ place by respondents (18\% of the responses). Our finding is also in contrast to Adebowale and Ogunlesi [8] who found that "supernatural causes" were the most acceptable etiological factor among both mentally ill patients and their relatives in southwest Nigeria.

Only $1.0 \%$ of respondents admitted that financial distress or poverty was a possible cause of mental disorder. Such a low score in the face of the present adverse socio-economic conditions prevailing in Nigeria may be explained by the Hausa cultural cum religious belief in providence and patience in the face of adversity. Other factors have also been reported by investigators as being associated with perceived causes of mental illness among patients and their relatives. Srinivasan and Thara [14] found that patient gender and education, duration of illness, the key relative's education, and the nature of relationship were associated with family beliefs about the cause of mental illness. 
There was a higher score on the preference for modern medical care in treating psychiatric illness. Similar changes in attitude towards the modern scientific approach regarding mental disorders was documented by Alem et al [15] in their work on mental illness in Ethiopia and by Iliyasu and Last [11].

Fear and avoidance of the mentally sick was frequent among female respondents. Traditionally, men are expected to be outwardly brave and less submissive towards aggression. The high frequency of negative attitudes among our respondents may be due to the fact that the concept of the mentally sick has an unfavourable public image. It has been shown that people may evaluate mental illness negatively, reject and discriminate against mental patients, and base their views on traditional stereotypes $[4,10,16]$.

Literacy was found to be significantly associated with positive attitude towards the mentally sick. Similar findings were reported by Madianos et al. [17] in Greece, and by Alem et al. [15] in Ethiopia. A study on community attitudes towards the mentally ill in New Zealand also reported that those who had previous contact with the mentally ill held informed and enlightened views [18]. Interestingly, a recent Hong Kong study reported a generally negative attitude towards the mentally ill despite a fairly good knowledge of mental illness among the respondents [19]. Our results support the hypothesis by Wolff et al. [19] that negative attitudes towards the mentally ill are fuelled by a lack of knowledge.

\section{Conclusions}

This study demonstrates the need for educational programs aimed at demystifying mental illness. A better understanding of mental disorders among the public would allay fear and mistrust about mentally ill persons in the community as well as lessen stigmatization towards such persons. Our findings may be of utility to health policy makers in the design of community mental health education programs and community mental health services in existing primary health centers in Nigeria.

\section{Competing interests}

None declared.

\section{Authors' Contributions}

$\mathrm{KM}$ and IZ initiated the study, and participated in the field work. IZ and AIS did the preliminary analysis and wrote the draft manuscript. KM, AIS and IZ participated in the design of the study and performed the statistical analysis. $\mathrm{KM}, \mathrm{IZ}$, and AIS participated in its design and coordination. AMH, KM and IZ wrote the final version of the draft manuscript. All authors read and approved the final manuscript.

\section{Acknowledgements}

The authors are indebted to the Chairman of Kura Local government and the village head of Karfi village for granting permission for this study to be conducted. We also wish to thank the field workers and medical students of Bayero University, Kano, Nigeria, who diligently collected the data.

\section{References}

I. WHO: Mental health care in developing countries: a critical appraisal of research findings. Report of a WHO Study Group. World Health Organ Tech Rep Ser 1984, 698:5-34.

2. Frenk J, Bodadilla JI, Sepulveda J, Lopez-Cervantes M: Health transition in middle-income countries: new challenges for health care. Health Policy Plan 1989, 4:29-39.

3. WHO: The World Health Report 200I. Mental health: New understanding; new hope [http://www.who.int/whr200I/200I/]. WHO, Geneva

4. Bhugra D: Attitudes towards mental illness. A review of the literature [review]. Acta Psychiatr Scand 1989, 80: I-12.

5. Trute B, Teffte B, Segall A: Social rejection of the mentally ill: a replication study of public attitude. Soc Psychiatry Psychiatr Epidemiol 1989, 24:69-76.

6. Wolff G, Pathare S, Craig T, Leff J: Community attitudes to mental illness. Br J Psychiatry 1996, 168: I83-90.

7. Asuni T, Schoenberg F, Swift C, editors: Mental health and disease in Africa. 2nd edition. Ibadan: Spectrum Books Ltd; 1994:42-53.

8. Adebowale TO, Ogunlesi AO: Beliefs and knowledge about aetiology of mental illness among Nigerian psychiatric patients and their relatives. Afr J Med Med Sci 1999, 28(I-2):35-4I.

9. National Population Commission: National Census, Federal Republic of Nigeria. Official Gazette 1997, 25:16.

10. White SR: Family experience with mental health problems in Tanzania. Acta Psychiatr Scand 199I, 83:77-III.

II. Iliyasu M, Last M: Mental illness at Goron Dutse Psychiatric hospital. Kano Studies, Special issue 1991, 3:41-70.

12. Holzinger A, Kilian R, Lindenbach I, Petscheleit A, Angermeyer MC: Patients' and their relatives' causal explanations of schizophrenia. Soc Psychiatry Psychiatr Epidemiol 2003, 38: I55-62.

13. Pfeifer S: Belief in demons and exorcism in psychiatric patients in Switzerland. BrJ Med Psychol 1994, 67:247-58.

14. Srinivasan TN, Thara R: Beliefs about causation of schizophrenia: do Indian families believe in supernatural causes? Soc Psychiatry Psychiatr Epidemiol 2000, 36:134-40.

15. Alem A, Kebede D, Woldesemiat G, Jacobsson L, Kullgren G: The prevalence and socio-demographic correlates of mental distress in Butajira, Ethiopia. Acta Psychiatr Scand Suppl 1999, 397:48-55.

16. Jorm AF, Griffiths KM, Christensen H, Korten AE, Parslow RA, Rodgers $B$ : Providing information about the effectiveness of treatment options to depressed people in the community: a randomized controlled trial of effects on mental health literacy, help-seeking and symptoms. Psychol Med 2003, 33:I07I-9.

17. Madianos MG: Changes in public attitude towards mental illness in Athens area. Acta Psychiatr Scand 1999, 99:73-78.

18. $\mathrm{Ng} \mathrm{SL}$, Martin JL, Romans SE: A community's attitudes towards the mentally ill. N Z Med J 1995, 108:505-8.

19. Wolff G, Pathare S, Craig T, Leff J: Community knowledge of mental illness and reaction to mentally ill people. BrJ Psychiatry 1996, 168:191-8.

\section{Pre-publication history}

The pre-publication history for this paper can be accessed here:

http://www.biomedcentral.com/1472-698X/4/3/prepub 